\title{
A Case of Primary Hyperparathyroidism with Low Serum Alkaline Phosphatase Levels
}

\author{
Nobuo KUGAI, Satoshi KIMURA*, KoIchi KAWAI, \\ KAMEJIRO YAMASHITA, ETSURo OGATA**, \\ SEIzo YOSHIKAWA and Yoshihide FUJIMOTO \\ Institute of Clinical Medicine, University of Tsukuba, \\ Sakura-mura, Ibaraki-ken 305, Japan
}

\begin{abstract}
A 23-year-old man with primary hyperparathyroidism which was typical except for reduced alkaline phosphatase activity is reported. Histological examination of surgical specimens revealed chief cell hyperplasia of the parathyroid glands. Systemic abnormalities of alkaline phosphatase were demonstrated, i.e., marked reduction of all isoenzymes and undetectable osseous enzyme in the serum, abnormal distribution of the enzyme in hepatocytes and diminished enzyme activities in leukocytes. In addition, diminished bone remodeling activity was revealed in a biopsy specimen of the rib. The association of hypophosphatasia is highly unlikely, because of normal urinary excretion of phosphoethanolamine, lack of osteomalacia, and no indication of an hereditary factor. The causal relationship between low remodeling activity and abnormalities in alkaline phosphatase was suggested.
\end{abstract}

With the increasing use of multichannel autoanalyzers for the measurement of serum calcium in routine laboratory exminations, more and more patients with primary hyperparathyroidism are being diagnosed. The association of primary hyperparathyroidism with such various metabolic bone diseases as Paget's disease, osteomalacia and postmenopausal osteoporosis has been documented.

Increased serum alkaline phosphatase activity in patients with primary hyperparathyroidism is a well recognized biochemical feature of the disease (Dent and Harper, 1962; Hodgkinson, 1963). In this communication, we report a case of primary

Received March 17, 1980.

* Present address: National Cancer Center, Tsukiji, Chuo-ku, Tokyo 104, Japan.

** Present address: The Fourth Department of Internal Medicine, Faculty of Medicine, University of Tokyo, Mejirodai, Tokyo 112, Japan. hyperparathyroidism with the unusual finding of diminished alkaline phosphatase activity in serum and in some tissues.

\section{Methods}

Serum and urinary calcium were measured by the orthocresolphthalein complexone method (Counertry and Briggs, 1966) using a Hitachi 706D autoanalyzer. The plasma parathyroid hormone concentration was determined by radioimmunoassay (Arnaud et al., 1971) using a standard derived from culture media of human parathyroid adenoma (standarized to hyperparathyroid plasma and kindly supplied by Dr. C. D. Arnaud). The concentration of 25-hydroxycholecalciferol $\left(25 \mathrm{OHD}_{3}\right)$ in ethanol extract of plasma was determined by competitive protein binding assay (Belsey et al., 1974) and 1, 25-dihydroxycholecalciferol $\left[1,25(\mathrm{OH})_{2} \mathrm{D}_{3}\right]$ was determined by radioreceptor assay after extraction of the metabolite from plasma by Sephadex LH-20 and high pressure liquid chromatography (Eisman et al., 1976). The urinary phosphoethanolamine was determined by column chromatography with the technique of Moore-Stein (Rasmussen, 1968). The fractionation of the isoenzymes of serum 
alkaline phosphatase was performed by disc gel electrophoresis (Smith et al., 1968). Ultracytochemical localization of alkaline phosphatase was performed by the lead citrate method (Mayahara et al., 1967). Alkaline phosphatase in leukocytes was stained by the naphthol AS-MX phosphate-fast blue RR method (Tomonaga et al., 1963). Histological examination of the bone was performed on a mineralized section of the biopsy specimen (Villauneva, 1967).

\section{Case Report}

A 23-year-old man was admitted to the University Hospital of Tsukuba in August, 1977 with lumbago and numbness of the lower extremities. Since the age of 18 , he had intermittently experienced lumbago and numbness of the soles of his feet. At 21, he noticed a gradual progression of weakness in both legs and had difflculty even in driving a car. He was taking no antacids, diuretics or vitamin D. His past history was not contributory. His father and an elder brother were slightly short in stature $(151 \mathrm{~cm}$ and $154 \mathrm{~cm}$, respectively).

On physical examination, he was 152 $\mathrm{cm}$ ( $-2.8 \mathrm{SD}$ from the mean for his age) and weighed $49 \mathrm{~kg}$. There was no skeletal deformity. The smooth, moderately firm liver was felt $2.5 \mathrm{~cm}$ below the right costal margin, and the tip of the spleen was felt $1 \mathrm{~cm}$ below the left costal margin.

On laboratory examination, there was slight polycythemia with an erythrocyte count of $5.5 \times 10^{6} / \mathrm{mm}^{3}$ and a hemoglobin concentration of $17.8 \mathrm{~g} / \mathrm{d} l$. The leukocyte count was $9.2 \times 10^{3} / \mathrm{mm}^{3}$ with a normal hemogram. The serum calcium and phosphorus levels were 11.4 and $2.1 \mathrm{mg} / \mathrm{d} l$, respectively. The serum alkaline phosphatase activity was $1.3 \mathrm{King}$-Armstrong Units (normal range, 2.6 to $10.0 \mathrm{U}$ ), the serum urate $8.1 \mathrm{mg} / \mathrm{d} l$. Results of urinalyses, ECG, stool examination, serological tests including Creactive protein, and other serum chemistry (protein, urea nitrogen, creatinine, transaminases, lactic dehydrogenase, cholinesterase, amylase, sodium, potassium, and chloride) were normal. The serum alkaline phosphatase values for the family members, including father and elder brother, were normal (father; 5.0, elder brother; 5.9 KingArmstrong Units). Arterial blood $\mathrm{pH}$ and bicarbonate were normal. The renal function as determined by PSP excretion, concentrating capacity and creatinine clearance was normal. X-rays of the chest and abdomen and excretory urogram were normal. A scintigram of the liver disclosed minimolly enlarged liver and spleen.

A diagosis of primary hyperparathyroidism was made, based on the parathyroid function tests (see Results). Neck exploration revealed hyperplasia of four parathyroid glands (left upper; $200 \mathrm{mg}$, left lower ; $100 \mathrm{mg}$, right, upper; ca. $100 \mathrm{mg}$, and right lower; $100 \mathrm{mg}$ ). Subtotal parathyroidectomy, leaving $1 / 2$ of the right upper gland was performed. Histological diagnosis was chief cell hyperplasia. After surgery, the serum calcium and phosphorus returned to normal $(9.0 \mathrm{mg} / \mathrm{d} l$ and $3.0 \mathrm{mg} /$ $\mathrm{d} l$, respectively) and the muscle weakness improved. The serum alkaline phosphatase level remained low after surgery.

Laparoscopy showed a slightly enlarged liver and spleen with normal appearance and consistency. Histological examination of the biopsy specimen disclosed minimal fatty degeneration of hepatocytes and minimal fibrotic change in Glisson's capsules.

\section{Results}

\section{Specific Tests of Parathyroid Function}

The serum calcium concentration ranged from 11.0 to $11.4 \mathrm{mg} / \mathrm{d} l$ and was not suppressed by $30 \mathrm{mg}$ prednisolone daily for 10 days. Serum phosphorus concentrations were 2.1 to $2.6 \mathrm{mg} / \mathrm{d} l$.

After equilibration for 5 days with a diet of $500 \mathrm{mg}$ calcium and $1000 \mathrm{mg}$ phosphorus, the values for tubular reabsorption of phosphate were 74.6 to $76.7 \%$. Urinary 


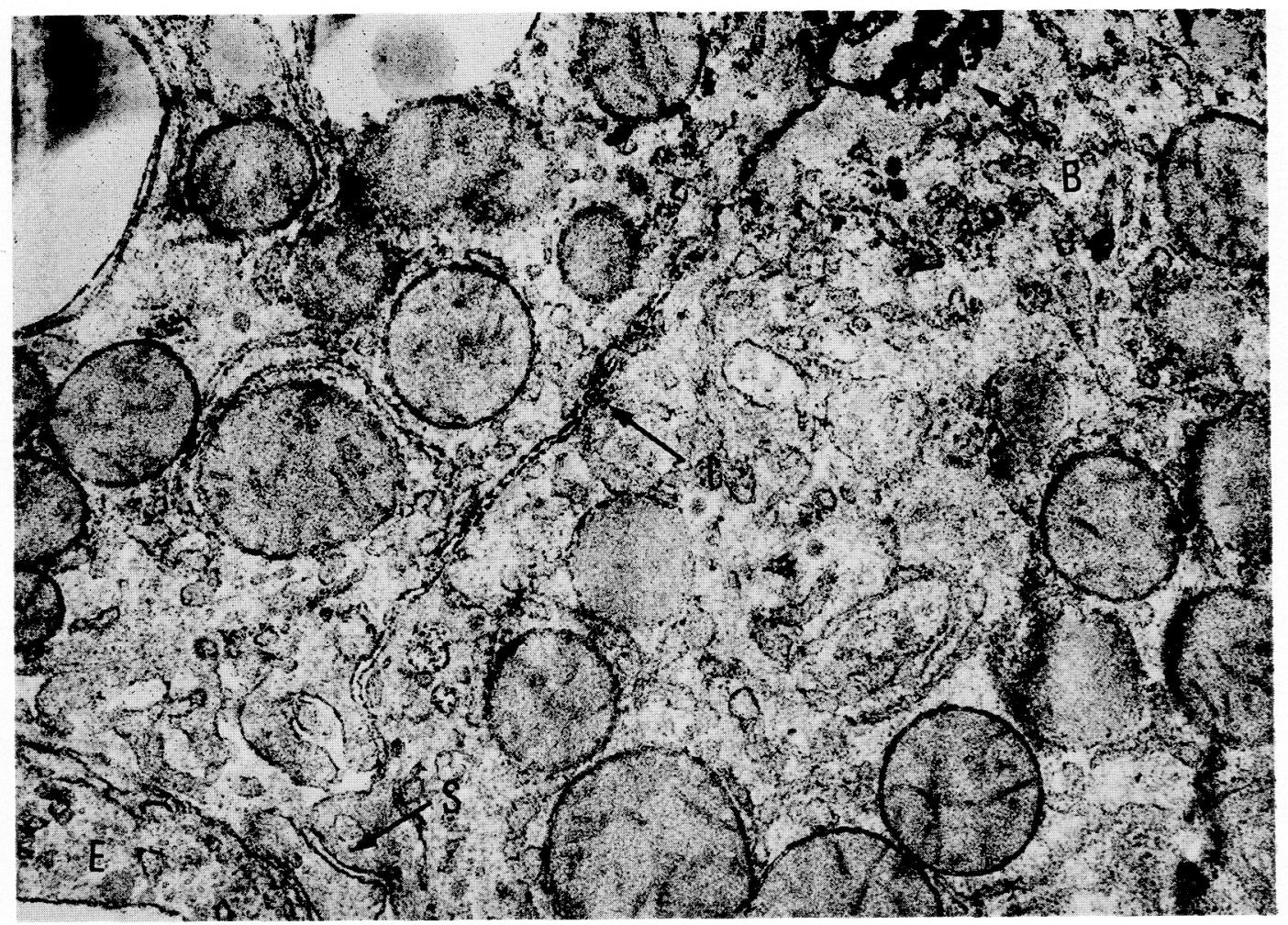

Fig. 1. An electron micrograph of hepatocytes in the biopsy specimen. The biopsy specimen was treated by the "lead citrate" method (Mayahara et al., 1967) for electron microscopic observation. Electron-dense particles indicating alkaline phosphatase activity distributed mainly on the bile canalicular membranes (B) and along the intercellular membranes (I), but scarcely on the sinusoidal membranes (S). E: Sinusoidal endothelium. $\times 19,000$

excretion of calcium ranged from 126 to $151 \mathrm{mg} /$ day.

The plasma immunoreactive parathyroid hormone concentration (iPTH) was $80 \mu \mathrm{lEq} /$ $\mathrm{m} l$ (normal, less than $40 \mu l \mathrm{Eq} / \mathrm{m} l$ ). Concentrations of $25 \mathrm{OHD}_{3}$ and $1,25(\mathrm{OH})_{2} \mathrm{D}_{3}$ in plasma were $24 \mathrm{ng} / \mathrm{ml}$ (normal rage, 14 to $42 \mathrm{ng} / \mathrm{ml}$ ) and $36.2 \mathrm{pg} / \mathrm{m} l$ (normal range, 17.2 to $45.6 \mathrm{pg} / \mathrm{ml}$ ), respectively. Urinary hydroxyproline ranged from 23 to $36.5 \mathrm{mg}$ / day (normal range, 15 to $40 \mathrm{mg}$ day). Xray examination of the skeleton showed no subperiosteal resorption, fracture, Looser's zone or osteopenia.
Specific Examinations of Alkaline Phosphatase Activity

The activity of serum alkaline-phosphatase ranged from 1.3 to 2.3 King-Armstrong Units on multiple determinations. Disc gel electrophoresis of the serum disclosed faint fractions of hepatic and intestinal alkaline phosphatase enzymes but no fraction of the osseous enzyme.

The distribution of hepatic alkaline phosphatase in the biopsy specimen was. studied by electron microscopy. The alkaline phosphatase stains were mainly distributed on the bile canalicular membranes. and on the intercellular membranes of the hepatocytes (Fig. 1). 


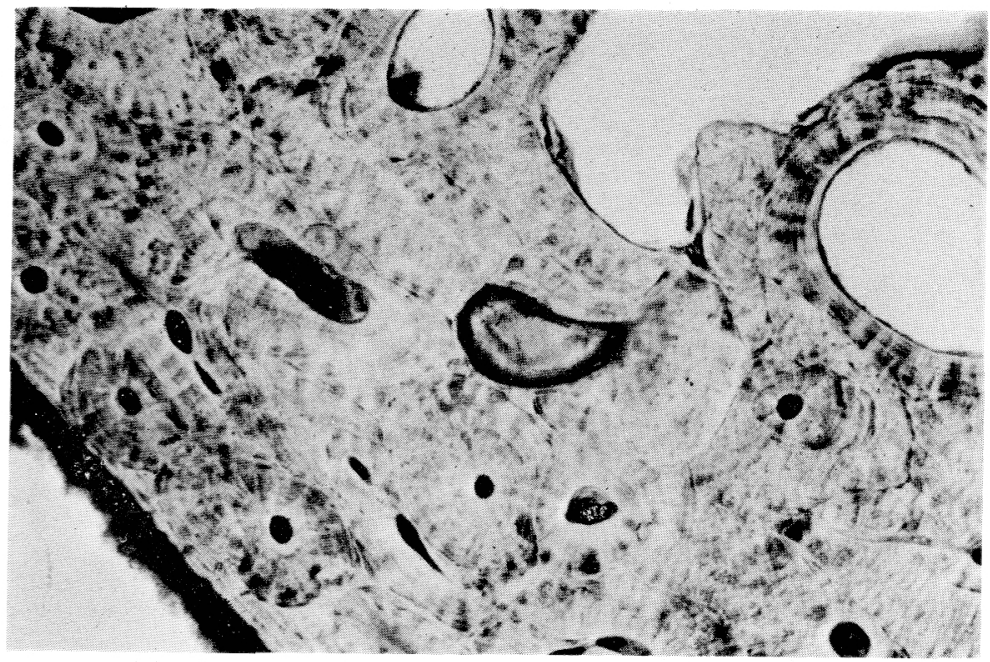

Fig. 2. An undecalcified section of the biopsy specimen from the rib. The section is stained by the osteochrome method ( $\mathrm{Ta}$ kahashi, 1970) and shows normal osteoid amount and width, and a reduced number of osteons and resorptive cavities with osteoid. Actual numbers for these measurements are referred to in the text. $\times 80$

Hematological examination showed that the number and activity score of the leukocytes positive to alkaline phosphatase stain in the peripheral blood smear were slightly diminished; positive rate $59 \%$ (normal range, 60.5 to $99.5 \%$ ), score 177 (normal range, 169.5 to 335 ) (Tomonaga and Hiwatashi, 1967).

The urinary excretion of phosphoethanolamine was 69 and $91 \mu \mathrm{mol} / \mathrm{g}$ creatinine (normal value, $75 \pm 19 \mu \mathrm{mol} / \mathrm{g}$ creatinine) (Licta, et al., 1978) on two separate occasions.

\section{Histological Examinations of the Bone}

Histological examination of the biopsy specimen from the rib revealed no indication of osteomalacia (Fig. 2) and calcification front, osteoid amout, osteoid width (10 $\mu \mathrm{m}$ ), and tetracycline uptake (about 90\%) were all normal.

The number of osteons with osteoid was diminished; $0.15 / \mathrm{mm}^{2}$ compared to normal value of $0.78 / \mathrm{mm}^{2}$ (Takahashi, 1970) for the age range 20 to 29 . The number of resorptive cavities with osteoid was also diminished; $0.34 / \mathrm{mm}^{2}$ compare to normal value of $1.69 / \mathrm{mm}^{2}$ (Takahashi, 1970). Thus diminished bone remodeling activity was indicated.

\section{Discussion}

The biocheminal findings in this case are typical of primary hyperparathyroidism: elevated serum calcium concentrations not suppressed by prednisolone, diminished serum phosphorus concentrations with low tubular reabsorption of phosphate, and elevated plasma level of iPTH. A clinical diagnosis of primary hyperparathyroidism was confirmed by the surgical and the histological findings. The diagnosis was further supported by the clinical and biochemical improvement after subtotal parathyroidectomy.

The diminished alkaline phosphatase activity seen in this patient is rare in primary hyperparathyroidism. As far as we are aware, such a phenomenon has been reported previously in only one case of primary hyperparathyroidism associated with hypophosphatasia (Faas et al., 1974). In hypophosphatasia the serum and tissue enzymes may be low, but high urinary phos- 
phoethanolamine excretion and osteomalacia are expected (Rasmussen, 1968). The possibility of hypophosphatasia in the present case is highly unlikely because urinary excretion of phosphoethanolamine was normal, there was no evidence of osteomalacia in the bone biopsy specimen nad other family members had normal serum alkaline phosphatase activity.

Moreover, present data suggest that the diminished serum alkaline phosphatase activity in this case reflects a systemic abnormality rather than an abnormality of the enzyme in a specific organ: 1) Osseous enzyme fraction was undetectable in serum; 2) Other fractions of the enzymes were very low in serum; 3) Abnormal distribution of the enzyme stained in hepatocyte which will be discussed below; Alkaline phosphatase stained slightly infrequently and less intensely in peripheral leukocytes. This constellation of abnormalities in alkalinephosphatase has never been described previously, to the best of our knowledge.

In the present case, the enzyme in the liver was distributed mainly on the bile canalicular membranes and on the intercellular membranes of the hepatocytes, in contrast to normal livers where the enzyme is distributed mainly on the bile canalicular membranes and on the sinusoidal membranes (Kako et al., 1978). The stain of alkaline phosphatase on the intercellular membranes has been documented only in cases of obstructive jaundice (Kako et al., 1978). However, in such instances the serum enzyme levels are high, and the enzyme is detected in increased amounts everywhere in the hepatocytes.

Although our patient had minimal hepato-splenomegaly, the liver as well as the spleen appeared normal on laparoscopy. No abnormal data were obtained in routine laboratory examinations. Thus, currently at least, the abnormality in the alkaline phosphatase distribution in his hepatocytes does not appear to be induced by liver disease.

No further studies were performed on the function of leukocytes. However, the patient lacked evidence of impairment of leukocyte function, such as susceptibiiity to infections.

As indicated by the bone biopsy study, a striking observation is the paradoxically diminished bone remodeling activity in spite of high levels of circulating iPTH. Since the activity of osseous alkaline phosphatase fraction in the serum appears to reflect osteoblastic bone formation, the absence of the osseous enzyme in the serum in this case suggests the lack of remodeling activity of the bone. In support of this theory, the urinary excretion of hydroxyproline was low in the face of biochemically evident primary hyperparathyroidism. We therefore suspect that there is some abnormality in the susceptibility of the bone or of alkaline phosphatase inbone to parathyroid hormone, which is causally related to the diminished bone remodeling activity in our patient. If it is allowable to assume that the diminished response of the bone to parathyroid hormone results in stimulation of the secretion of the hormone by an unknown factor, through a feedback mechanism other than caicium, this will explain the pathogenesis of the hyperplasia of the parathyroid glands. In any case, as the present study is the first report on the combination of this constellation of alkaline phosphatase abnormalities with primary hyperparathyroidism, further information is needed before a conclusion can be drawn. The present study indicates that when one encounters patients with primary hyperparathyroidism and diminished serum alkaline phosphatase activity, a clinical diagnoses of hypophosphatasia should be made very cautiously. 


\section{Acknowledgements}

The authors wish to thank Drs. Tatsuo Suda (Showa University) and Yasuho Nishii (Chugai Laboratory) for measuring $25 \mathrm{OHD}_{3}$ and $1,25(\mathrm{OH})_{2} \mathrm{D}_{3}$, respectively.

The authors are grateful to Drs. Shiro Iino (University of Tokyo), Makoto Kako (Hamamatsu Medical College), and Yasuhiro Yoda (University of Tsukuba) for specific studies on alkaline phosphatase in serum, liver and leukocytes, respectively.

The authors are also indebted to Dr. Hunter Heath III for his helpful comments in the preparation of this manuscript.

This study was supported in part by a grant from Ministry of Education, Science and Culture of Japan.

\section{References}

Arnaud, C. D., H. S. Tsao and T. Littledike (1971). J. Clin. Invest. 50, 21.

Belsey, R. E., H. F. DeLuca and J. T. Jr. Potts (1974). J. Clin. Endocrinol. Metab. 38, 1046.
Counertry, H. V. and A. R. Briggs (1966). Am. J. Clin. Pathol. 45, 290.

Dent, C. E. and C. M. Harper (1962). Lancet 1, 559.

Eisman, J. A., A. J. Hamstra and B. E. Kream (1976). Arch. Biochem. Biophys. 176, 235.

Faas, F. H., C. L. Wadkins, J. S. Daniels, G. R. Davis, W. J. Carter and J. O. Wynn (1974). Clin. Orthop. Relat. Res. 101, 216.

Hodgkinson, A. (1963). Clin. Sci. 25, 231.

Kako, M., H. Kimura, M. Torii, T. Nakajima, G. Toda, K. Kanai and T. Oda (1978). J. Clin. Electron. Microsc. 11, 478.

Licta, A. A., N. Radfar, F. C. Barther and E. Bou (1978). Am. J. Med. 64, 133.

Mayahara, H., H. Hirano, T. Saito and K. Ogawa (1967). Histochemie 11, 88.

Rasmussen, K. (1968). Dan. Med. Bull. 15 Suppl. 2,1 .

Smith, I., P. J. Lightstone and J. D. Derry (1968). Clin. Chim. Acta 19, 499.

Takahashi, H. (1970). J. Jpn. Orthop. Ass. 44, 283. (In Japanese)

Tomonaga, M. and J. Hiwatashi (1967). Jpn. J. Clin. Pathol. 15 Suppl. 13, 41. (In Japanese)

Tomonaga, M., T. Sasaki and M. Okuzaki (1963). Acta Haematol. Jpn. 26, 179. (In Japanese)

Villauneva, A. R. (1967). Am. J. Clin. Pathol. 47, 78. 